International Scientific Journal Theoretical \& Applied Science

p-ISSN: 2308-4944 (print) e-ISSN: 2409-0085 (online)

Year: 2017 Issue: $11 \quad$ Volume: 55

Published: 24.11.2017 http://T-Science.org
Elzada Abdymomunovna Abdymomunova candidate of juridical science assistant professor of department of Criminal Procedure of Academy of Minirstry of Internal Affairs of Kyrgyz Republic

SECTION 32. Jurisprudence.

\title{
ABOUT SOME COLLISIONS IN CONCEPTUAL-TERMINOLOGICAL INSTRUMENT OF THE CRIMINAL PROCEDURE CODE OF KYRGYZ REPUBLIC
}

Abstract: The article contains proposals aimed at improving the current legislation. It also presents the author's wording of the terms "data" and "grounds".

Key words: sufficiency, evidence, concept, data, sufficient grounds, criminal proceedings.

Language: Russian

Citation: Abdymomunova EA (2017) ABOUT SOME COLLISIONS IN CONCEPTUALTERMINOLOGICAL INSTRUMENT OF THE CRIMINAL PROCEDURE CODE OF KYRGYZ REPUBLIC. ISJ Theoretical \& Applied Science, 11 (55): 162-166.

Soi: http://s-o-i.org/1.1/TAS-11-55-18 Doi: crossef https://dx.doi.org/10.15863/TAS.2017.11.55.18

\section{К ВОПРОСУ НЕКОТОРЫХ КОЛЛИЗИЙ, ИМЕЮЩИХСЯ В ПОНЯТИЙНО- ТЕРМИНОЛОГИЧЕСКОМ АППАРАТЕ УГОЛОВНО-ПРОЦЕССУАЛЬНОГО ЗАКОНОДАТЕЛЬСТВА КЫРГЫЗСКОЙ РЕСПУБЛИКИ}

Аннотация: Статья содержит предложения, направленные на совершенствование действующего законодательства. Также в ней представлены авторские формулировки терминов «данные» и «основания».

Ключевые слова: достаточность, доказательства, понятие, данные, достаточные основания, уголовное судопроизводство.

\section{Introduction}

Проблема толкования нормативно-правовых актов существовала еще в Древнем Риме. Властвующие лица были наделены правом разъяснять законы, а в отдельных авторитарных государствах право толковать законы предоставлялось лишь одному лицу императору. Так, толковал законы только император Юстиниан [1].

\section{Materials and Methods}

В Уголовно-процессуальном законодательстве Кыргызской Республики достаточно часто встречаются такие термины, которые порождают неоднозначные, двусмысленные толкования, что в свою очередь приводит к ошибкам, неправомерным решениям. В связи с чем, правильное толкование норм уголовно-процессуального законодательства играет важную роль в их применении. По мнению Осипова А.В., необходимость толкования права вызвана следующими причинами: «оказание помощи в интерпретации смысла, значения и логической связи нормы права; объяснение терминов и юридических конструкций при изложении государственной воли, содержащейся в нормах права; несовершенство и неадекватное использование законодательной техники; отсутствие ясного, точного, понятийного языка нормативного акта, то есть наличие двусмысленных и расплывчатых формулировок» [2, с. 442]. Как справедливо отмечает Морозова Л.А. «толкование - сложный интеллектуально-волевой процесс, направленный на установление точного смысла правовой нормы, раскрытие выраженной в ней воли законодателя»[3, с. 299]. По данному вопросу в свое время высказывал свое мнение и Фойницкий И.Я., отмечая, что «толкование может производиться по точному разуму и по общему смыслу, что необходимо при неполноте, 
неясности или противоречии норм закона, причем толкование по точному разуму производится в том случае, когда нет в понимании нормы существенных сомнений, и толкование по общему смыслу свойственно при наличии сомнений относительно действительного значения и объема содержащихся в законодательстве правил», [4, с. 177]. с которым соглашается и Ольков С.Г., отмечая, что «всякая научная теория, или концепция, должна быть непротиворечивой, работать, приводить к управляемым, контролируемым и предсказуемым последствиям» [5, с. 141]. Так, в уголовнопроцессуальном законодательстве Кыргызской Республики достаточно часто встречаются такие понятия как «достаточные данные», «достаточные основания», «достаточно доказательств».

На первый взгляд может показаться, что данные термины используются как тождественные. Однако, следует отметить, что суть данных понятий отличается своей значимостью. Зачастую, практикующие юристы, практические работники, адвокаты, не различают суть и содержание указанных понятий и не обращают им должного внимания. Однако следует отметить, что именно ошибочное понимание таких терминов как тождественные влекут за собой многочисленные нарушения норм уголовно-процессуального законодательства.

В Словаре русского языка под ред. С.И. Ожегова даются следующие понятия: «данные сведения, необходимые для какого-нибудь вывода, решения»; «основания - причина, достаточный повод, оправдывающие что-нибудь» [6]. Информационные технологии своим развитием подтолкнули и развитие понятийного аппарата. «Данные (от лат. data) - это представление

фактов и идей в формализованном виде, пригодном для передачи и обработки в некотором информационном процессе» [7].

Под данными в научной литературе предлагают понимать «различные предусмотренные законом источники информации и соответствующее содержание данной информации» [8]. Представляется, что следует разделять понимание источников данных и самих данных как информации.

Ныне действующий Уголовнопроцессуальный кодекс определяет доказательства как фактические данные, на основе которых в определенном законом порядке следователь, прокурор, суд устанавливают наличие или отсутствие деяния, предусмотренного Уголовным кодексом, совершение или несовершение этого деяния подозреваемым, обвиняемым, подсудимым и виновность либо невиновность подсудимого, а также иные обстоятельства, имеющие значение для правильного разрешения дела (ст. 81 УПК КР). Эти данные устанавливаются:

1) показаниями подозреваемого, обвиняемого, подсудимого, потерпевшего, свидетеля;

2) заключением эксперта;

3) вещественными доказательствами;

4) протоколами следственных и судебных действий;

4-1) результатами оперативно-розыскной деятельности, полученными в установленном законом порядке;

5) другими документами.

Новопринятый УПК КР изменил нормативное понимание доказательств, заменив понятие «фактические данные» на термин «сведения». Ряд ученых, в свою очередь, определяли фактические данные как «информацию, сведения о фактах, подлежащих установлению по делу» [9].

Таким образом, изменения в законодательстве, связанные с понятием доказательства, носят лишь терминологический характер, сохранив по существу свое содержание. Речь по-прежнему идет об информации, связанной с обстоятельствами совершения преступления.

Понятие «данные» в уголовном судопроизводстве, с учетом изложенного, является тождественным понятию «фактические данные», и может быть сформулировано следующим образом: это информация об обстоятельствах произошедшего, связанная с событием преступления, исследованная субъектом доказывания, которая может быть положена в основу принятия процессуального решения, а также формирует убеждение должностного лица о необходимости его проведения.

«Основания», в свою очередь, представляют собой причину, повод, ответ на вопрос, почему принято указанное решение либо проведено следственное действие. Указанное понятие характеризует причинно-следственную связь между имеющимися «данными» и выводом из них.

Под «достаточными основаниями» в уголовном судопроизводстве следует понимать повод, совокупность причин, позволяющих признать принятое процессуальное решение обоснованным и мотивированным.

Примером, наглядно демонстрирующим это различие, является положение ч. 2 ст. 150 УПК, в соответствии с которым «основанием к возбуждению уголовного дела является наличие достаточных данных, указывающих на 
совершение преступления. Каждый термин в указанной статье использован в соответствии с его значением.

Причиной принятия решения о возбуждении уголовного дела является наличие достаточных данных (сведений) об обстоятельствах произошедшего преступления, указывающих на его совершение.

В этом случае подчеркивается как наличие в распоряжении должностного лица, принимающего решение, сведений об обстоятельствах произошедшего, так и важность логического вывода о факте совершения преступления.

Один из аспектов «достаточного основания» заключается в том, что убедительность любого вывода прямо пропорциональна его обоснованности, для реализации которой привлекаются все законы и правила [10]. Необходимо подчеркнуть, что понятие «достаточные основания» является оценочносубъективным понятием.

Закон, устанавливая строгие правила поведения сторон обвинения и защиты, не может охватить все возможные варианты развития событий, происходящие на практике.

Действующий УПК КР указывает на необходимость наличия достаточных оснований для применения меры пресечения (ст. 102 УПК КР), достаточных данных для возбуждения уголовного дела (ч.2., ст. 150 УПК КР) и т. д.

Нормы действующего уголовнопроцессуального законодательства, регламентирующие производство следственных действий, содержат оба термина. Провести разграничение между ними достаточно проблематично. К примеру, при наличии достаточных оснований полагать, что предметы, документы или сведения, имеющие значение для уголовного дела, могут содержаться соответственно в бандеролях, посылках или других почтово-телеграфных отправлениях либо в телеграммах или радиограммах, на них может быть наложен арест (ст.187 УПК КР), а основанием для производства обыска является наличие достаточных данных полагать, что в помещении или ином месте либо у лица могут находиться орудия преступления, предметы, документы и ценности, которые могут иметь значение для дела (ст. 184 УПК КР).Данные следственные действия больше чем другие могут нарушить конституционное право граждан на частную жизнь, жилище, в связи с чем, они проводятся лишь на основании судебного решения.

Судебная практика также не делает различия между данными понятиями.

Встает закономерный вопрос, существует ли необходимость в дифференциации понятий «достаточные основания» и «достаточные данные» для целей уголовного судопроизводства, реализации прав обвиняемого, потерпевшего, соблюдения требований закона при проведении следственных действий и принятии иных процессуальных решений.

Указанные различия являются существенными для правоприменителей. Появление единого подхода к вопросу о сведениях, которые могут быть положены в основу принятия процессуальных решений, является необходимым условием для укрепления законности в уголовном судопроизводстве.

Анализ действующего уголовнопроцессуального законодательства показывает, что законодателем термин «достаточные данные» использован в тексте УПК КР четыре раза, «достаточные основания» - восемь раз. При этом лишь в одном случае (ч. 4 ст. 331-29 УПК КР) достаточные основания

упоминаются на стадии судебного разбирательства: «Если председательствующий признает, что обвинительный вердикт вынесен в отношении невиновного и имеются достаточные основания для постановления оправдательного приговора ввиду того, что деяние, в совершении которого вердиктом подсудимый признан виновным, не содержит состава преступления, то он выносит постановление о роспуске коллегии присяжных заседателей и направлении уголовного дела на новое рассмотрение иным составом суда со стадии предварительного слушания».

Думается, что таким образом законодатель намеренно призвал судебные органы при принятии итогового процессуального решения оперировать лишь доказательствами, а не «данными», либо «основаниями», носящими вероятностный и не всегда процессуальный характер.

Представляется, что законодателем в ряде случаев необоснованно, вопреки их содержанию и смыслу, использованы понятия «данные» и «основания». Понятие «достаточные данные» упоминается законодателем в статьях 12, 142, 150, 184 УПК КР. Его использование имеет место при рассмотрении вопроса о применении мер безопасности в отношении потерпевшего, свидетеля или других участвующих в деле лиц, а также членов их семей или близких родственников, в случае угрозы насилием, уничтожением или повреждением имущества либо иными опасными противоправными действиями; при определении основания для принятия решения о возбуждении уголовного дела, при производстве следственного действия обыска.

Особый интерес представляет вопрос, связанный с производством и обоснованием 
причин производства следственных действий. Схожие по существу следственные мероприятия: производство обыска (ст. 184 УПК КР) и производство личного обыска ( ст. 185 УПК КР) содержат разные термины, «достаточные данные» в первом случае и «достаточные основания»- во втором.

Причинами этого противоречия, по всей видимости, являются недостатки юридической техники, поскольку обосновать его с позиции закона не представляется возможным. Более того, относительно других следственных действий, а также в случае избрания меры пресечения, принятия иных мер процессуального принуждения законодатель вновь использовал формулировку «достаточные основания полагать».

В данной связи необходимо отметить отсутствие закономерности в использовании законодателем терминологии, что непосредственно влияет и на разницу в толковании схожих норм.

Аналогичным образом законодателем использовано понятие достаточных данных в гражданско-процессуальном законодательстве. Судья в порядке подготовки к судебному разбирательству дела о признании гражданина недееспособным при наличии достаточных данных о психическом расстройстве гражданина назначает для определения его психического состояния судебно-психиатрическую экспертизу (ст. 284 ГПК КР).

Дело об административном правонарушении может быть возбуждено должностным лицом, уполномоченным составлять протоколы об административных правонарушениях, только при наличии одного из поводов, предусмотренных п. 1, ст. 547 К.оАО, и достаточных данных, указывающих на наличие события административного правонарушения.

Недостатком формулировки «достаточные основания полагать», на наш взгляд, является ее акцент на причинную связь, а не на содержательную составляющую. Представляется, что в целях большей конкретизации закона следует изменить статьи, содержащие понятие «достаточные основания». Указание, к примеру, на наличие «достаточных данных, свидетельствующих о том», что обвиняемый, подозреваемый скроется от следствия или суда, будет свидетельствовать о совокупности сведений и логическом выводе, что лицо может скрыться. Такая формулировка позволит создать унифицированный подход к принятию процессуальных решений и исключить имеющееся в законе противоречие.

Понятие «достаточные основания» в тексте УПК КР должно быть заменено на термин «достаточные данные». Изменению подлежат статьи 102, 116, 118, 119, 184, 188, 188-1, 331-29 УПК КР.

Это позволит конкретизировать сведения, необходимые для принятия решений о производстве следственных действий, создать последовательность, по которым возможно оценить наличие достаточных данных в той или иной ситуации и, соответственно, обоснованность принятого решения.

\section{Conclusion}

Декларируя цель создания единообразной практики применения уголовно-процессуального закона, в том числе и в тех случаях, когда субъектам уголовного судопроизводства предоставляется возможность принятия процессуальных решений по своему внутреннему убеждению на основе собранных сведений о фактах, законодатель, тем не менее, не провел четкой разделительной линии между следственными действиями, для проведения которых требуется сбор «достаточных данных» либо наличие «достаточных оснований».

При принятии процессуальных решений субъектами уголовного судопроизводства основное внимание должно уделяться вопросу достаточности собранных данных, которые закладываются в основу решений.

\section{References:}

1. Frantsiforov YU.V. (2017) «Tolkovaniye norm ugolovno-protsessual'nogo zakona kak sposob razresheniya protivorechiy $\mathrm{v}$ ugolovnom sudoproizvodstve».

2. Osipov A.V. (1997) Tolkvaniye prava// Teoriya gosudarstva i prava/ pod red. N.I. Matuzova i A.V. Mal'ko. - M., 1997. p. 441-442.
3. Morozova L.A. (2002) Tolkovaniye prava // Teoriya gosudarstva i prava. - M., 2002. p.299.

4. Foynitskiy I.YA. (1996) Kurs ugolovnogo sudoproizvodstva. - SpB., 1996. T1. p.171-177.

5. Ol'kov S.G. (1998) Biosotsial'naya mekhanika, obshchestvennaya patologiya i tochnaya yurisprudentsiya. Tyumen', 1998. p. 141. 
\begin{tabular}{l|lrl|l|ll} 
& ISRA (India) & $=\mathbf{1 . 3 4 4}$ & SIS (USA) & $=\mathbf{0 . 9 1 2}$ & ICV (Poland) & $=\mathbf{6 . 6 3 0}$ \\
Impact Factor: & ISI (Dubai, UAE) $=\mathbf{0 . 8 2 9}$ & PUHL (Russia) $=\mathbf{0 . 2 0 7}$ & PIF (India) & $=\mathbf{1 . 9 4 0}$ \\
& GIF (Australia) & $\mathbf{0 . 5 6 4}$ & ESJI (KZ) & $=3.860$ & IBI (India) & $=\mathbf{4 . 2 6 0}$ \\
& JIF & $\mathbf{1 . 5 0 0}$ & SJIF (Morocco) & $=\mathbf{2 . 0 3 1}$ & & \\
\hline
\end{tabular}

6. Ozhegov S.I. (1991) Slovar' russkogo yazyka. M.: Russkiy yazyk, 1991. p. 155, 461.

7. Granichin O.N., Kiyayev V.I. (2013) Informatsionnyye tekhnologii $\mathrm{v}$ upravlenii. M.: BINOM, 2013. p. 17.

8. Volodina N.V. (2015) Nekotoryye osobennosti sudebnoy ekspertizy $\mathrm{v}$ grazhdanskom i arbitrazhnom protsesse sovremennoy Rossii // Yustitsiya. 2015. № 1. p. 2.
9. Leybnits G.V. (1982) Soch. T. 1. M.: Mysl', 1982. S. 27. (Filosofskoye naslediye).

10. Petrov A.V. (2011) Dostatochnyye dannyye neobkhodimoye usloviye dlya vozbuzhdeniya ugolovnogo dela // Zakonnost'. 2011. № 2. p. 57-59.

11. Selina Ye.V. (2014) Ugolovno-pravovaya zashchita zakonnoy protsedury ugolovnogo sudoproizvodstva // Pravovaya initsiativa. 2014. № 3. p. 12. 